\title{
RACISMO RELIGIOSO: POLÍTICA, TERRORISMO E TRAUMA COLONIAL. OUTRAS LEITURAS SOBRE O PROBLEMA
}

\section{RELIGIOUS RACISM: POLITICS, TERRORISM AND COLONIAL TRAUMA. OTHER READINGS ON THE PROBLEM}

\author{
Luiz Rufino \\ Marina Santos de Miranda ${ }^{2}$
}

Recebido em: 07/2019

Aprovado em: 09/2019

\begin{abstract}
Resumo: Este artigo, em caráter ensaístico, tem como principal questão interrogar a dimensões do racismo religioso via um debate político/epistemológico tecido em diálogo com conceitos assentes na esteira dos estudos sobre crítica ao colonialismo, relações étnico-raciais, linguagem, poder e política. Assim, tendo como cenário recente o aumento significativo de eventos de violência contra as comunidades de terreiro, reivindicamos pensa-los como atos de terror. Esses atos se manifestam no aporte de uma ampla, diversificada e sofisticada engenharia produtora de escassez e trauma que tem raça/racismo como alicerces. Nesse sentindo, trabalharemos com as perspectivas teóricas apontadas nos conceitos de carrego colonial (Rufino e Simas, 2019) e esquizorracialidade (Miranda, 2018), afim de apresentar hipóteses de como as ações de terrorismo vem se configurando como ataques não somente aos corpos físicos e territórios de seus praticantes, mas também como ofensiva as dimensões sensíveis e profundas da existência.
\end{abstract}

Palavras-Chave: Racismo Religioso; Trauma Colonial; Terrorismo.

\begin{abstract}
This article, on an essay basis, has as main question to interrogate the dimensions of religious racism via a political/epistemological fabric debate in dialogue with concepts based on studies on criticism of colonialism, relations ethnic-racial, language, power and politics. Thus, having as a recent scenario the significant increase of events of violence against the communities of Terreiro, we claim to think them as acts of terror. These acts are manifested in the contribution of a broad, diversified and sophisticated engineering producing scarcity and trauma that has race/racism as foundations. In this sense, we will work with the theoretical perspectives pointed out in the concepts of colonial carry (Rufino and Simas, 2019) and Schizorraciality (Miranda, 2018), in order to present hypotheses of how the actions of terrorism have been configured as attacks not Only to the physical bodies and territories of its practitioners, but also as offensive the sensitive and profound dimensions of existence.
\end{abstract}

Keywords: Religious Racism; Colonial Trauma; Terrorism.

\footnotetext{
${ }^{1}$ Professor da Universidade do Estado do Rio de Janeiro- Faculdade de Educação da Baixada Fluminense (UERJFEBF). Doutor em Educação (UERJ), Pós-doutorado em Relações Étnico-Raciais (PPRER/CEFET). Membro do Laboratório de Etnografia e Estudos em Comunicação, Cultura e Cognição (LEECCC-UFF.

${ }^{2}$ Antropóloga (UFF), Mestranda em Antropologia (PPGA-UFF). Membro do Laboratório de Etnografia e Estudos em Comunicação, Cultura e Cognição (LEECCC-UFF).
} 


\section{Das obras coloniais, seus efeitos e atualizações}

No Brasil na última década se registrou uma crescente nos casos de violência contra as populações de terreiro ${ }^{3}$. Esses acontecimentos popularmente identificados como atos de intolerância religiosa nos possibilitam interrogar alguns problemas que nos cercam há tempos e codificam a dinâmica da vida em um mundo que se substancia pelos efeitos da guerra e das energias geradas pelo racismo/colonialismo. Dessa forma, ao longo desse texto investiremos no levantamento de algumas questões e na inscrição de hipóteses que nos abrem caminhos para um giro político/epistemológico nos debates sobre a chamada intolerância religiosa. Para o desenvolvimento dessa proposta temos como orientação aqui dois principais conceitos que alinhavam toda a reflexão, são eles carrego colonial (Rufino e Simas, 2019) e esquizoracialidade (Miranda, 2018).

Temos como orientação a compreensão que o colonialismo nos legou heranças múltiplas. Nesse sentido, as obras coloniais continuam a atuar na manutenção e aprofundamento dos traumas, já que as mesmas não se restringem a operar somente na concretude das coisas, assim extrapolam os limites do corpo físico e atingem as dimensões sensíveis da existência. Partimos da proposta de Rufino e Simas (2019), que pensam esses efeitos de terror como uma espécie de carrego colonial. Em outras palavras, para os autores, o carrego colonial opera como um sopro de má sorte que nutre o assombro e vigência de um projeto de dominação que atinge os diferentes planos da existência do ser (2019, p. 21).

Nesse tom, levantamos uma questão e a mesma marca posição diante a necessidade de encarar a complexa engenharia das obras coloniais e propor artimanhas que perspectivem despachar os seus carregos. Perguntamos: por que a chamada intolerância religiosa emerge como uma noção que não assume a raça/racismo, uma vez que, os mesmos são elementos estruturantes do fenômeno que a mesma busca pensar? Assim, a noção estaria a mistificar o racismo na medida que escolhe qualificar, enquanto intolerância, a violência sofrida?

Em contrapartida, parte dos problemas de caráter político/epistemológico gerados pela noção de intolerância religiosa são enfrentados quando os encaramos como sendo racismo religioso. A noção de racismo religioso dá conta de marcar que grande parte das violências sofridas por determinadas culturas e comunidades são encarriladas por uma engenharia de

3 Tomamos de empréstimo o termo povo de terreiro ou populações de terreiro para designar as comunidades de praticantes dos múltiplos ritos negro-africanos e ameríndios inscritos no Brasil. Assim, temos como principais referências nesse complexo os candomblés, umbandas, omolocôs, juremas, encantarias, minas e batuques. 
dominação/subordinação que tem a raça/racismo/colonialismo como matrizes/motrizes de desenvolvimento do mundo moderno. Nessa perspectiva, racismo religioso é uma expressão que abre caminho e conquista espaços relevantes na luta antirracista no Brasil. Entretanto, tendo o colonialismo como um sistema complexo, inacabado e ambivalente, identificamos que mesmo reconhecendo o avanço proposto pela noção que traz a raça/racismo para o foco do problema ainda encontramos limites no que tange a indexação do termo religião/religioso, já que a mesmo produz uma simplificação das dimensões cosmológicas, ontológicas, filosóficas e políticas de múltiplas culturas.

Assim, o que queremos destacar é que diante da demanda de discussão e proposição de ações antirracistas e transgressoras dos parâmetros coloniais haveremos de exercitar outras formas de sentir/fazer/pensar. A noção de racismo religioso mesmo cumprindo função tática na luta contra as violências sofridas pelos povos de terreiro emerge também como uma expressão que carrega a ambivalência da experiência e construções coloniais. Então, para nós é fundamental interpelar os termos, os seus respectivos usos e impactos nas relações, linguagens, cotidianos e na produção de subjetividade.

Dessa maneira, o que se entende como religiões de matrizes africanas, ameríndias ou práticas de terreiro tem se constituído ao longo de séculos como uma ampla e variada rede pluriversal (Ramose, 2011) referenciada por gnoseologias múltiplas, políticas cotidianas que resguardam orientações éticas, estéticas e tecnologias ancestrais de potencialização da vida. É fundamental ressaltarmos que o termo religião no contexto da experiência colonial deve ser interpelado e atravessados por diferentes inscrições e escutas. As populações de terreiro, os praticantes das políticas e tecnologias ancestrais historicamente subalternizadas tem autonomia, propriedade moral, comunitária e ancestrálica para definir seus termos e agendas. Somado a isso, o que buscamos enquanto interlocutores dessa discussão é apontar que a experiência do racismo religioso como tem se constituído nos últimos tempos se expressa como terrorismo.

Sobre as ações de terror aos povos de terreiro, suas comunidades, patrimônios e saberes é oportuno mais uma vez o diálogo com o conceito de carrego colonial (Rufino e Simas, 2019), destacando que só é possível a manifestação do mesmo diante o imperativo de uma lógica de dominação contrário a vida em toda sua diversidade. Assim, o colonialismo enquanto uma engenharia que em primeira instancia mira ações nos limites da fisicalidade das coisas prossegue incessantemente em uma escala de destruição de múltiplas esferas da existência, desde a psíquica a espiritual. Nessa lógica, esse sistema investe na linguagem como uma das principais formas de exercício de seu poder. 
Como base nessa reflexão, o que fica para nós enquanto indício é que a destruição de terreiros, não meramente como ato de depredação ou intolerância, mas como um complexo de violências integradas atua na necessidade de conter e aniquilar sistemas produtores de vida. Assim, do ponto de vista ontológico, da radicalidade da experiência do ser, os terreiros se inscrevem como tempo/espaços de remontagem de existências que foram assaltadas pelo terror colonial. Do ponto de vista, político, epistemológico e pedagógico os terreiros cumprem também remontagens de identidades, saberes, gramáticas e suas respectivas formas de ensinoaprendizagem.

Na busca do alargamento da reflexão sobre o terrorismo praticado contra as populações de terreiro, estabelecemos diálogo com alguns pensamentos. Assim, a nossa conversa entende que nos atos de terror, que vão desde invasões, depredações, incêndios, humilhações, desterros, ameaças de morte, interdição de rituais em espaços públicos e assassinatos está a operar uma complexa engenharia colonial que desdobra o racismo em ações de cosmofobia (Santos, 2015), colonialidade cosmogônica (Walsh, 2009), epistemicídio (Carneiro, 2005), semiocídio (Sodré, 2017), comunitaricídio (Grosfoguel, 2018), psicopolítica (Hun, 2018) e necropolítica (Mbembe, 2018).

Dessa maneira, não seria exagerado estabelecermos como hipótese que parte dos fundamentos que sustentam o terrorismo contra as populações de terreiro estão imbricados aos conceitos apresentados acima. Assim, sobre a cosmofobia (Santos, 2015) inscreve-se as dimensões da recusa, repulsa e desejo de aniquilação de complexos explicativos de mundo não brancos e ocidentais. Colonialidade cosmogônica (Walsh, 2009) nos possibilita pensar como a obra colonial se debruçou sobre outras formas de existência, significação e interação de mundo, as alterando, capturando e as subordinando a lógica dominante. Essa lógica, na medida que inscreve uma narrativa de interdição sobre o outro, também legítima a própria presença e atuação do sistema opressor.

Sobre os conceitos de epistemicídio (Carneiro, 2005), semiocídio (Sodré, 2017) e comunitaricício (Grosfoguel, 2018) na relação com as experiências de terror vivida pelos povos de terreiro podemos articular também, como contraponto, uma complementaridade das esferas do conhecimento, linguagem e exercício do ser nos modos de vida dos povos de terreiro. Nesse sentido, ambos conceitos nos levam a pensar como os ataques estabelecem vínculos com a lógica de edificação do Ocidente-europeu e toda sua agenda de terror colonial. Assim, as ações de violência investem na fratura e aniquilação das esferas de conhecimento, linguagem e organização da vida que sejam contrárias a política de dominação. Nessa via, discutimos que 
essas ações operam de maneira sofisticada e múltiplas atentando contra esferas de conhecimentos tradicionais, de formas de significação, comunicação, interação de mundo e na destruição da comunidade como ponto necessário para a edificação do processo civilizatório.

Com base nos diálogos postos acima podemos sair em defesa de que o que está em jogo é uma ampla disputa em prol da vida, que na inscrição das práticas de terreiro se vinculam a uma agenda em favor da diversidade, que tem a luta antirracista e a transgressão dos parâmetros coloniais como orientação política/epistemológica. Assim, elencar também os conceitos de psicopolítica (Hun, 2018) e necropolítica (Mbembe, 2018) como estratégicos para o entendimento da estruturação e operação do poder, da violência e da economia no nosso tempo é também pertinente para pensar o caráter dos fenômenos aqui discutidos. Para Hun (2019), a psicopolítica nos permite problematizar não mais o controle do corpo, mas a psique, o desejo. Assim, mira-se não somente a exploração, mas se passa a produzir a auto-exploração. Por sua vez, a necropolítica (Mbembe, 2018) irá nos provocar a pensar que não há lugar para todos em uma lógica que explora a rentabilidade do assassinato como plano de desenvolvimento. Ambos conceitos ainda nos levariam a investir em outros desdobramentos que problematizariam as relações entre o mercado, teologia-política e militarização da vida.

Porém, ainda ficam perguntas diante as violências sofridas pelos povos de terreiro. Em depoimento uma das yalorixás que teve seu barracão de candomblé destruído, em um contexto em que os criminosos forçaram a sacerdotisa a destruir seus próprios bens, definiu a experiência em duas palavras: vergonha e humilhação. Sobre a humilhação, Fanon (2008), nos lembra que é uma das formas táticas que o racismo tem de incutir no ser o desvio existencial, lançá-lo em uma condição vacilante, aprisioná-lo na zona do não ser. Em outra situação um sacerdote também vítima de violência se questiona: por que a sociedade nos odeia?

Consideramos em diálogo com Mauss (2003), que o fenômeno social do ódio pode ser considerado em uma perspectiva sociológica um fato social total. Tem como característica uma tessitura complexa que envolvem os vários aspectos do contrato social e das normas constitutivas do direito à vida. Sua relação com a formação da mentalidade social do país está fundamentada em um legado escravagista impregnado na alma do país. Cabe assinalar que o extermínio da vida não se restringe às características marcadamente inerentes ao genocídio, aqui falamos da suspensão da possibilidade de viver, através dos múltiplos fatores que compõem as condições para se estar vivo. Dessa maneira, para dar conta desta experiência o 
conceito de maafa cunhado por Marimba Ani(1988) é desejável, por se tratar de um holocausto físico, espiritual, psíquico e emocional.

Uma outra dimensão a ser evidenciada é da perseguição através das marcas identitárias que penetram todas as estruturas institucionais. Estas criam imagéticas das "essencialidades" de sujeitos culturalmente já expostos a outras categorias de violência como gênero e classe. Cabe apontar, no entanto, que os elementos que projetam a raça como alvo excepcional do ódio, emanam de uma percepção profunda de que todas as expressões e saberes, dentre outros elementos constitutivos ou identificados como originários das presenças negro-africanas no mundo implicadas na noção de raça negra, geram ojeriza e devem ser sistematicamente aniquilados por força da engenharia racismo/colonialismo.

Diante das muitas possibilidades de abordagem estabelecemos diálogo entre os dois principais conceitos aqui apresentados. O carrego colonial (Rufino e Simas, 2019) no diz que, sob a inteligibilidade dos esquemas de terror do colonialismo, há o reconhecimento da memória e da ancestralidade como planos de reconstituição existencial (p.20). Assim, para os autores, a morte, signo que compreende muitos entenderes em um dizer, opera na lógica colonial como uma política de desencantamento (p.20). Nesse sentindo, esse sistema de terror que atua de maneira múltipla investe em dimensões como a humilhação e o esquecimento como formas de atentar contra a memória e a ancestralidade como planos éticos e de remontagem existencial.

Em segundo momento, através do conceito de esquizorracialidade (Miranda, 2018), se estabelecem alguns pontos para pensarmos esses eventos e as relações raciais. Primeiro, a esquizorracialidade convoca acerca de um fenômeno que na pratica é um evento dialético, individualizado e em seu caráter é também um fenômeno coletivo. Segundo aspecto, no discurso é dotado de uma aparência moral - característica de uma sociedade igualitária e humanista- mas, se fundamenta como um sequestro da experiência evocada pela emoção racista a partir do ato de denegação. Terceiro, enquanto sintoma, é uma estratégia de bloqueio e desqualificação da experiência e da memória social das pessoas pretas. Por último é o uso dissimulado das identidades raciais que expressam oposições ou empatias de acordo com dada circunstância. Assim, são manifestadas na emoção dos sujeitos de acordo com o capital socialpolítico-epistêmico de vantagens e desvantagens.

No enlace dessa reflexão nos interessa pensar as dissimulações, as estratégias de terror,

\footnotetext{
${ }^{4}$ ANI, Marimba- LettheCircle Be Unbroken: The Implications of African Spirituality in the Diaspora. Ed.Nkonimfo Publications (1988), p. 60.
} 
as minúcias do trauma e as possibilidades de explosão, em termos fanonianos, no que diz respeito a trama que se tece em cada ato de violência cometido contra as populações de terreiro. Tendo em vista o caráter ensaístico desse texto levantamos algumas questões, traçamos hipóteses e convocamos um repertório conceitual que nos permita apontar caminhos.

\title{
Esquizorracilaidade: política de interdição da vida e produção do trauma
}

\begin{abstract}
"A diáspora negra é um acontecimento em aberto, é um contínuo. (...) Racismo/colonialismo/colonialidade marcam o nosso tempo. A raça e seus contratos de dominação (Mills, 2008) são os fundamentos alicerces da lógica colonial, perpetram a morte, aniquilamento, desencante e humilhação. A colonialidade é uma espécie de marafunda e carrego colonial, ela opera como um sopro de má sorte que mantêm o assombro e a vigência de um projeto de dominação nas dimensões do ser/saber/poder.” (Rufino, 2018).
\end{abstract}

É partindo desta assertiva que traçamos os caminhos por onde despachamos a intensa batalha travada no campo do discurso, sobre o drama do terrorismo religioso contínuo e sistemático nos cotidianos de seus praticantes. São muitos os acontecimentos que demonstram o investimento no estado de terror perpetrado contra as práticas de tradição africana/afrodiaspóricas/ameríndias no país. Destes tantos, destacamos as séries de ataques a terreiros de umbanda e candomblé na Baixada Fluminense no Rio de Janeiro de 2017 a 2018, e a ação judicial reivindicando o termino da nutrição e ritualização do alimento ${ }^{5}$ praticado pelos povos de terreiro.

Mirando os discursos de ataque e defesa, que desses eventos surgiram é notável que o dano tenha gerado traumas coletivos e recalcamentos no mundo concreto. A intenção aqui é destacar como operam - na ordem do comportamento violento e no discurso, o que aponta o conceito de esquizorracialidade - enquanto um regime de dissimulações intencionais ou nãointencionais, que acabam validando ou retirando o mérito de reivindicações cruciais para os sujeitos que sofrem seus efeitos, muitas vezes, pelo mero desejo de interdição moral, legal e física do exercício de suas vidas, essas orientadas por outras visões de mundo, ou seja, uma política de produção de sentido não-branca, não dominante.

Alguns casos emblemáticos nos auxiliam nessa empreitada. $\mathrm{O}$ caso que envolve a judicialização da prática do abate de animais em terreiros de matriz africana, teve a sentença proferida em março de 2019. A sentença foi favorável aos povos de terreiro. Neste expediente,

\footnotetext{
${ }^{5} \mathrm{O}$ caso está nos tribunais do Rio grande do Sul desde agosto de 2018 e chegou ao Supremo Tribunal Federal no inicio de 2019 encerrando em março deste mesmo ano.
} 
o Estado Brasileiro reconhece o racismo religioso, a subalternização e feitichização das práticas de matriz africana no Brasil. Após a decisão, centenas de ativistas pela defesa dos animais, veganos e cristãos manifestaram-se nas redes sociais ${ }^{6}$, repetindo acusações de realidades infundadas sobre as imolações nos rituais sagrados, divulgando fotos de conteúdo agressivo, ignorando todas as argumentações exaustivamente postadas por adeptos do culto, incluindo as que constam do processo judicial.

Nesse sentido, muitos dos comentários feitos pelos defensores do fim da sacralização de animais, desejaram a morte explicitas de macumbeiros, com o argumento que os mesmos poderiam simplesmente atualizarem seu culto. Condenaram também as populações negro/africana por trazerem em sua cultura tal pratica. Esses fatos dão o tom das vibrações existentes nos cotidianos que se expressam como parte do caráter do carrego colonial, como um legado que assombra modos de vida (Rufino e Simas, 2019). Essas mesmas dimensões também assentam a esquizorracialidade como categoria de análise que dá conta de que a emoção racista se funde nos vácuos da memória social e é a mola mestra do extermínio (físico e simbólico) que revelam o fetiche pela possessão das culturas e das pessoas negro/africanas.

No segundo exemplo, apontamos os sucessivos ataques a terreiros da Baixada Fluminense que resultaram - e continuam resultando - em diversas mobilizações em torno de respostas. A mídia deu conta de que os ataques foram realizados por traficantes e milicianos de origem neopentecostal, inflamados na politização do discurso de conversão e extirpação do mal. Como se pode supor, na realidade o alcance desta subordinação envolve ainda, agentes do Estado e a ramificação de uma ampla rede político-teológica. Dizemos isso a partir de um breve exercício etnográfico realizado em 2018 onde foram realizados alguns trabalhos voluntários de monitoria.

Em dada ocasião foi presenciado a atuação de agentes de Degases ${ }^{7}$, unidade socioeducativa que na prática funciona como um sistema prisional para jovens em conflito com a lei situados na baixada do Rio de Janeiro. Eles desempenham o papel de verdadeiros inquisidores do cristianismo dentro das unidades, o que foi confirmado em conversa com alguns atendidos. Eles assim agiam baseados na tradição fundamental do próprio judiciário brasileiro recorrendo ao caráter inquisitorial de natureza cristã religiosa que opera como uma sensibilidade inerente ao ethos jurídico, (Lima, 2009).

\footnotetext{
${ }^{6}$ Ver em: https://natelinha.uol.com.br/famosos/2019/03/30/luisa-mell-critica-sacrificio-de-animais-em-cultos-einternautas-comentam-126724.php

${ }^{7}$ Novo DEGASE -Sistema Socioeducativo do Estado do Rio de Janeiro.
} 
Nessa perspectiva, o mesmo ethos é partilhado por agentes e esferas de controle policial - carcerário, mas dessa vez em seu caráter executor. Os agentes incorporam em nome do Estado a crença de que apenas pelo caminho da conversão pentecostal é possível retirar aqueles meninos, em sua maioria pardos e pretos, do ciclo de marginalização/morte a que estão submetidos. Assim, expressam estar convictos de que se trata da ausência de servidão, subjugação total, prestação de serviços a Deus e a igreja.

A maior parte do tempo dentro das unidades são preenchidas por atividades ocupacionais previstas pelo $\mathrm{ECA}^{8}$ e respectivamente nos artigos 19 , I e $5^{\circ}$, VI, da Constituição Federal. A realidade é que quase todo o tempo é preenchido por igrejas neopentecostais, durante a semana e fins de semana. A atuação das pastorais católicas existe, mas ocupam menor número atividades. Qualquer um pode se questionar: ué, o ECA garante a laicidade, onde estão as outras religiões? As outras religiões encontram barreiras estruturais de atuação, e, em algum nível, essas barreiras também se dão na comunidade institucional que possui um grande peso na decisão/operacionalização em ocupar qualquer espaço/tempo que seja dentro das unidades. Este fato é a razão pela qual pode-se afirmar que são dentro dessas unidades, que são recrutados, convertidos e treinados os "gladiadores do altar" e não apenas os que se integram a igrejas sobre o véu de uma boa abordagem social como muitos pensam. Alguns desses meninos apenados, declaram- se, inclusive, pertencentes a religiões de matriz africana, um deles, recém "convertido", me contou que foi punido por usar as folhas da bíblia, único objeto permitido sem restrições dentro das unidades, para confeccionar um origami.

Sublinho aqui a sofisticação da violência operada pelo ódio racial, no qual do primeiro para o segundo caso, a aplicação da violência dá conta que não há apenas uma política de interdição da vida atrelada aos modos de ser/saber, mas também um investimento na instrumentalização deste extermínio. Nesse sentido, existe uma lógica, em que muitas vezes, seus atores- sujeitados a extrema vulnerabilidade- e aproveitando-se dela para incrementar as narrativas de conversão, usando o pertencimento daquele convertido como prova cabal da salvação. Percebam que a partir disso, a violência simbólica e verbal dos discursos próconversão desvelam-se em extermínio armado (necropólítica), controle das subjetividades (psicopolítica) e territorial (comunitaricídio). Além disso, representam também a formação de um exército paramilitar comprometido em dar cabo deste plano de poder a muito tempo

\footnotetext{
${ }^{8}$ Estatuto da Criança e do Adolescente. Ver em: https://www.jusbrasil.com.br/topicos/10619587/artigo-3-da-lein-8069-de-13-de-julho-de-1990

${ }^{9}$ Ver reportagem sobre em: http://koinonia.org.br/noticias/lembra-deles-gladiadores-do-altar-da-igreja-universalserao-investigados $/ 5460$
} 
elaborado. Qualquer um de nós poderia se perguntar: Mas o que afinal tais eventos têm a ver com a esquizorracialidade?

Pode-se dizer que a esquizorracialidade possui um decurso fenomenológico processual sobre as mentalidades. Atuam nas interações sociais deste fenômeno, contaminando o senso comum no âmbito das linguagens e da percepção da realidade - no universo das ciências psíquicas, poderia ser descrita como uma dissonância cognitiva (FESTINGER, 1957).

A quem não interessa proteger os animais ou manter os jovens infratores fora dos bairros? Que mal um juiz (a) veria na atuação de pastores que professam uma fé atrelada a moral, paz, a caridade e comunhão? A propósito da imaginação social de que o cristianismo se apresenta em todas as tradições religiosas, a hegemonia cristã é propagada como verdade, oficialmente desde da adoção da educação religiosa em 1931no Brasil. Esta disciplina foi atualizada no acordo entre o estado Brasileiro e a Santa Sé em 2009, sem falar dos livros didáticos distribuídos e financiados pelas arquidioceses e igrejas evangélicas em 2000, onde é ensinado que Oxalá e Olorum são os outros nomes, ou traduções dos nomes dados a Deus/Jesus Cristo (Caputo, 2012).

Essa produção/distorção dos discursos, atuam na dimensão interpessoal e na dimensão social-coletiva. Seu efeito se dá nos lócus do deslocamento entre a razão e o ato de negação psicológica $^{10}$ (Figueiredo Junior, 2013). É razoável implementar medidas que reforçam valores benéficos a sociedade, mas na prática, a evangelização realizada com base na demonização, submissão física e cultural, fixam-se a imagética do corpo e da mentalidade negra. A negação desta natureza negativa e essencialista, radica-se como ponto de apoio e salvação (Fanon, 2008.).

Por outro lado, muitas vezes o discurso de apoio e pertencimento do povo de terreiro está contaminado por essas mesmas incoerências. Não raro são discursos que reforçam regimes de verdade e comportamentos, baseiam-se no mesmo teor das mentalidades cristãs, tamanha a penetração desse sentimento no tecido social. As tensões produzidas pelas relações raciais nos terreiros são refratarias das relações estabelecidas a partir das desigualdades que circunscrevem o racismo nos vários aspectos de toda a sociedade. Desta forma, o modelo dominante contingência desarranjos nas estruturas de crenças, refletindo grande presença de brancos nas estruturas mais elevadas do culto afrodiaspórico, conferindo-lhes, neste lugar, uma forte

\footnotetext{
${ }^{10}$ Segundo o autor, a denegação é um fenômeno mental e linguístico cuja contraparte lógica é pautada da abstração dos contextos a que estão inseridos, nestes termos, apesar de não considerar aceitável certas afirmativas, ele a afirma porque acredita que é, somente.
} 
representatividade e acesso diferenciado. Nessas relações e em suas desproporções percebemos a acentuação das interfaces raça/classe, uma vez que há a manutenção de privilégios seja constituído pelas inscrições assentes na raça como fator de distinção, mas também no que tange a aspectos econômicos.

A discriminação é nesses espaços, algo fortemente condenável, diria qualquer pessoa oriunda dessas culturas. Por esse motivo, é muito comum que negros e brancos pertencentes as comunidades de terreiro afirmem a mesma natureza de suas origens espirituais (muitas vezes até parentais) para legitimar seu pertencimento e isto é muito comum em situações em que a negritude é reivindicada como elemento constitutivo importante das tradições afro-diaspóricas. Apesar disso, a prática do racismo em terreiros revela-se nos detalhes das atividades laborais a transformação imagética de orixás africanos em um elemento culturalmente lógico e subalterno para sociedade branca/escravocrata, entre outros comportamentos racistas já bastante naturalizados e descrito no trabalho de campo de onde emerge a potência para pensarmos a esquizorracialidade.

Cabe dizer que a enorme contribuição do apagamento histórico sobre as contribuições negras no país, e o pioneirismo de seu legado para o mundo, acabam por impulsionar a imaginação subalterna associada a imagem do preto/escravo. Sobre esse aspecto ainda se somam características de natureza eugenista, amplamente propagadas no século XX, das quais inúmeras disciplinas consideradas de ponta no Brasil têm origem. Não é incomum que muitas das afirmativas neste trecho sejam cotidianamente desqualificadas e desmentidas, ou mesmo, que disparem alguma angustia aos leitores. Essas afirmativas - fruto da revisão de pesquisas frente a novas evidências e propostas - invertem, muitas vezes o olhar sobre o branco na sociedade e denuncia as atrocidades praticadas ao longo de séculos.

A imaginação sobre o poder, intrinsecamente atrelada a imagem das pessoas brancas, é historicamente associada a benevolência, a moral, a civilidade, a beleza e a decência de seres dotados de compaixão e nobreza, e que naturalmente podem e devem dispor daquilo que desejarem (KILOMBA, 2010). Apoiados no antagonismo psíquico negro apontado por Kilomba e Fanon (2008), encaminhando-nos a pensar a interdependência dessas relações racialmente marcadas. Fanon defende que na condição de humano, o preto não poderia se contrapor as características inerentes ao imaginário humano-branco que significa o imaginário humano-hegemônico. Resta ao preto desta forma, incorporar a humanidade-branca e denegar a condição subalterna que lhe é atribuída.

Nesta cisão da psique, o fenômeno da esquizorracialidade se estabelece na ruptura do 
lugar psicológico, incapaz de reconhecer a si próprio como elemento de uma demanda sócio histórica. Ou seja, aquilo que não consegue se afastar da obsessão branco-possessiva da condição de proprietário, da melancolia, da autoridade para controlar o que vai ser absorvido da cultura, o que será legalizado ou moralmente aceito. Assenhorear e decidir deixar viver ou morrer, das implicações das questões de raça e do legado escravagista, ora obliterando, ora afirmando as identidades raciais dadas no contexto das relações racista. Tais dinâmicas ocupam da mesma forma as fendas em suas percepções e emoções a ponto de querer incorporar-se delas.

Estas observâncias são cognoscíveis a partir de três principais elementos identificados no campo da pesquisa ${ }^{11}$ em resumo: 1) a identidade racial branca é referencial, dotada de plena humanidade, potência e poder; 2) a identidade racial negra estabelecida a partir do antagonismo a identidade racial branca, e apenas a partir de escravidão (ser-escravo); 3) nas subjetivações operadas na dinâmica da cultura, que alternam aquilo que possui valor, que ameaçam as percepções coletivas já estabelecidas e aculturadas, que criam dissonâncias capazes de produzir ódio ou auto-ódio, desenraizamento ou confrontação com a origem; definição do outro ou auto definição subalterna; transvalorização a partir da mitigação da raiz cultural, a partir do que o sujeito nega e/ou projeta de si mesmo, ou ainda, algo que o associe a suas raízes étnicas ou ontológicas.

\section{Considerações finais, acabamento provisório}

Pensarmos as obras coloniais como engenharias de terror que continuam a vibrar e inferir ações de destruição contra a diversidade de existências e linguagens é umas das apostas que fazemos para o aprofundamento da reflexão acerca do racismo religioso. Assim, saímos em defesa da noção de esquizorracialidade não somente como um aporte para a problematização dos impactos dos atos de terrorismo, mas também para ampliarmos a leitura sobre os eventos de violência cometido aos povos de terreiro.

Nesse sentindo, esse texto buscou ser um primeiro ato diante de uma discussão que será continuada, mantendo investimentos de permanência do diálogo para que a mesma seja desdobrada. Assim, buscamos levantar questões e traçar hipóteses de investigação que esmiúcem os repertórios discursivos que estão sendo postos socialmente. Ao nosso ver, existe uma emergência em romper com uma certa economia discursiva que mantem a retórica da

\footnotetext{
${ }^{11}$ Ver (Miranda, 2018).
} 
intolerância religiosa como um fenômeno restrito a experiência da fé.

Em outra via, o que percebemos com os diálogos estabelecidos em campo e com a interlocução com conceitos que exploram análises sobre as relações raciais, a crítica ao colonialismo, a linguagem e os processos de subjetivação é que essas ações de violência, reivindicadas como atos de terror, estão implicadas na interdição das existências e suas respectivas práticas de saber. Ou seja, a problemática não se instaura meramente no âmbito de uma retórica discursiva sobre a fé ou da liberdade de culto, mas sobre dimensões mais radicais da ritualização da vida e das possibilidades de invenção de mundo.

Assim, pensar as questões entorno da chamada intolerância religiosa ou do racismo religioso, que mesmo com seus limites conceituais acreditamos ser o termo mais pertinente para questão posta, está diretamente implicado a uma revisão crítica sobre as possibilidades de existir aprisionados em um estado radicalizado na violência e inimigo da diversidade. Esse estado tem como alicerce e força motriz de sua engenharia a raça, racismo e a dominação colonial.

\section{Referências Bibliográficas}

ANI, Marimba (Dona Richard). Deixe o Círculo Ser Ininterrupto: As Implicações da Espiritualidade Africana na Diáspora. New York: Nkonimfo Publications, 1988 (orig. 1980).

CARNEIRO, Aparecida Sueli. A Construção do outro como não-ser fundamento do ser. Tese de doutorado. Programa de Pós-graduação em Educação da Universidade de São Paulo. São Paulo, 2005.

FANON, Frantz. Pele negra, máscaras brancas. Tradução de Renato da Silveira. Salvador: EDUFBA, 2008.

Os Condenados da Terra. Rio de Janeiro: Editora Civilização Brasileira S.A, 1968.

FESTIGER, Leon. Teoria da dissonância. Rio de Janeiro, Zahar, 1975.

FIGUEIREDO JUNIOR, Selmo Ribeiro. Denegaçao Psicológica- Aspectos linguísticos e lógicos. 2013. Universidade Federal do Paraná. Acessado em 31/3/2018https://acervodigital.ufpr.br/bitstream/handle/1884/34583/R\%20-\%20D\%20$\% 20$ SELMO $\% 20$ RIBEIRO $\% 20$ FIGUEIREDO $\% 20$ JUNIOR.pdf? sequence $=1 \&$ isAllowed $=\mathrm{y}$

GROSFOGUEL, Ramón. Para uma visão decolonial da crise civilizatória e dos paradigmas da esquerda ocidentalizada. In: Decolonialidade e pensamento diaspórico/ organizadores Joaze Bernardino-Costa, Nelson Maldonado-Torres, Ramón Grosfoguel. - 1. Ed- Belo Horizonte: Autentica Editora, 2018.

HAN, Byung- CHul. Psicopolítica - O neoliberalismo e as novas técnicas de poder. Nr. 1, autaut. Editora Ayné, Belo Horizonte. 2018. 
IZQUIERDO, I. Memória. Porto Alegre: Artmed, 2002.

IZQUIERDO, I. A arte de esquecer. Cérebro, Memória e Esquecimento. Rio de Janeiro: Vieira @Lent, 2004.

KILOMBA, Grada. The Mask. In: Plantation Memories: Episodesof Everyday Racism. Münster: Unrast. Cadernos de Literatura em Tradução, n. 16, p. 171-180. Portal de Revistas da USP, 2016.

MAUSS, Marcel. Ensaio sobre a Dádiva. São Paulo: Editora Cosac \&Naify, 2013.

MBEMBE, Achile. Necropolitics. Public Culture 15 (1):11-40 Copyright by Duke University Press. 2003.

MILLS, Charles W. O Contrato de Dominação. Meritum- Belo Horizonte- v.8-n²-p15-70jul/dez. 2013.

MIRANDA, Marina Santos de. “Ah, Branco, dá um tempo!’: Vestígios de Esquizorracialidade sobre a ótica da juventude de terreiro. Monografia de graduação em Antropologia (63p.). Universidade Federal Fluminense. Niterói, 2018

RAMOS, Alberto Guerreiro. Introdução crítica à sociologia brasileira. Rio de Janeiro: Editora UFRJ, 1995

ROMERO \& COSTA. Modelo Epigenético e Transtorno de Estresse Pos-traumático. Revista digital Neurociência em Debate, Maio de 2017. Acessado em 02/2018: http://cienciasecognicao.org/neuroemdebate/?p=3576

RAMOSE, Magobe. Sobre a legitimidade e o estudo da Filosofia Africana. Ensaios Filosóficos, Rio de Janeiro, v. IV, out. 2011.

RUFINO, Luiz \& SIMAS, Luiz Antonio. Flecha no Tempo. $1^{\circ}$ ed. - Rio de janeiro: Mórula, 2019.

SODRÉ, Muniz. Pensar nagô. Rio de Janeiro: Vozes, 2017.

WALSH, Catherine. Interculturalidade, Estado, Sociedad. Luchas (De) coloniales de nuestra época. Primeira edición: Universidad Andina Simón Bolívar/ Ediciones Abya-Yala, Quito. 2009. 